\title{
Research on the Lexical Chunks and Interactive Education Mode and the Corresponding Applications on Teaching of English Linguistics
}

\author{
Fei Zhu \\ HuangHuai University, \\ Zhumadian,Henan,463000 China
}

\begin{abstract}
In this paper, we conduct research on the lexical chunks and the interactive education mode and the corresponding applications on the teaching of English linguistics. The ultimate goal of the teaching is to improve the level of the students, exert students' initiative and creativity, in order to achieve this goal, teachers need to according to the teaching object, choose the appropriate teaching methods. , diversified teaching method is multivariate, teaching method of the multivariate interactive for teachers to provide a liberal idea, on the teaching method all rivers run into sea, not stick to one method, in order to further play the advantages of various teaching methods, optimizing classroom teaching, improve teaching efficiency and ensure the quality of teaching. Each teaching method has its advantages and disadvantages, comprehensive methods while the teachers can foster strengths and circumvent weaknesses, fully mobilize students' enthusiasm, exert students' initiative and creativity, and improve the level of students. Under this background, we integrate the lexical chunks and the interactive education mode to construct the novel education paradigm that is innovative.
\end{abstract}

Keywords-Lexical Chunks, Interactive Education, English Linguistics, Applications, Teaching.

\section{Introduction}

In the foreign language teaching, too much emphasis on language education theory knowledge of the traditional teaching concept has been unable to keep up with the current teaching reform. In the implementation and deepening of new curriculum innovation, higher request to the modern education teaching quality. In this context, constructivism learning theory is put forward, to pay attention to the development of students' language ability, at the same time, more attention to the whole development of students' personality, causes the student to improve the overall quality. Professor constructivism to the teacher's model is also put forward higher requirements [1-3].

Correspondingly, the course features of English major could be summarized as the follows. (1) The course of economic and social characteristics. The difference between English majors in different professional direction is not reflect the subject characteristics of English language course that is not in man on the development features of the humanities courses, and reflects the social and the economic development needs in the direction of professional courses. (2) The course of one's own development characteristics. Any course on people would have an impact on the development of people. So, from the perspective of presupposition, English major courses have function to promote the development of students. (3) The course features. English specialized subject characteristic mainly reflects in the English language classes. The courses including general English linguistics, the English vocabulary, English grammar, English textual linguistics and so on. They have to apart from the English major and other professional discipline curriculum characteristics.

English language belongs to a key course of English professional knowledge module, to cultivate the English professional talents play an important role. But in the English language teaching process problems, lead to curriculum teaching effect is not satisfactory. English language course covers wide range, too much content, concepts, inseparable, theory and 
practice. English language classes at the same time less, text difficulty is big. This course so that students more think of the English linguistics boring, tasteless and demanding.

Caused by the continuous development of the teaching content and linguistics expansion and the contradiction between teaching hours limited growing, if we still continue to use previous traditional teaching concept and teaching approach to teaching, we must can't adapt to the new situation of the teaching process, another kind of the better teaching methods must be adopted to make students and teachers to adapt themselves to the core requirements of the new situation as soon as possible. English linguistics course informative content is broad, is deep, profound theories, contents and is less class contradictions that easy to cause the student to have the fear to the English language course. So when choosing English linguistics course teaching content, appropriate to reduce the teaching content of the breadth and depth, a targeted teaching, clear learning task, choose the suitable practice method, guide students to actively complete the task. Under this background, we conduct research on the lexical chunks and interactive education mode and the corresponding applications on the teaching of English linguistics in this paper. Additionally, the figure one shows the corresponding keywords.

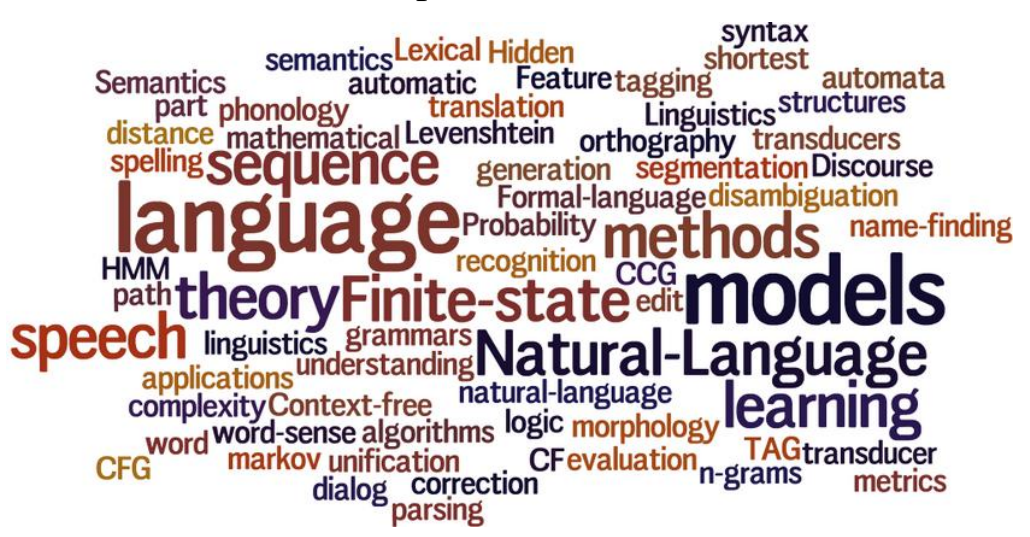

Figure 1. The Keywords of the Effective English Education Pattern

\section{Our Proposed Methodology}

The Interactive Education Mode. Interactive teaching is a kind of new teaching mode, in particular is a kind of humanistic thought in order to adapt to the modern society development direction has a demand of the reform in the education under the new situation. On the one hand, broadly speaking, interactive teaching refers to in the teaching process, the interaction between all the participants and their influence, it contains the in-class and after-class interaction; On the other hand, from the narrow sense, interactive teaching is a kind of special performance situation, pay attention to the interpersonal interaction of the in-class teaching forms and methods, teacher-student interaction is one of its main performance situation [4-5].

The characteristics of the interactive education mode could be generally summarized as the follows aspects. (1) The integrity of teaching elements. Between each element of teaching in college English teaching mode is not exist in isolation, in the process of the specific implementation of the model, need to fully consider the teaching high school students, teachers and course of balance between the relevant factors, the comprehensive evaluation, to realize the teaching goal of the teaching so as to achieve in the pattern and the clarity of teaching means. (2) Stronger practicability. College English interactive teaching mode, including the nature of language learning, the 
English teaching of foreign content and the content can facilitate students to master the language knowledge of the system. (3) Strong operability. College English interactive teaching mode is not only a complete set of theory, it has strong operability. It can be implemented based on students' different cognitive emotion in the learning English and learning conditions, comprehensive inspection related factors.

Teaching interactive surface structure is the form of teaching interaction and epitaxy as it can meet the requirements of the teachers and students in the interactive mode, quantity, but can't guarantee the quality of the interaction between teachers and students. Interactive teaching is the deep structure of teaching, the connotation and essence of directly decides the teaching quality and level of interaction. Even if the teaching interaction in the form of the same, if teachers at different levels for perception of the deep structure teaching interaction, teaching quality and the level of interaction will there is a big difference. According to the constructivism theory, the purpose of the learning is to make learners construct their own meaning, not just write down "correct answer" or imitate others. Learners must be independent use the existing experience, explore the meaning of the own so as to construct their own understanding of the world and in constructivism theory and the theory of communicative language teaching, on the basis
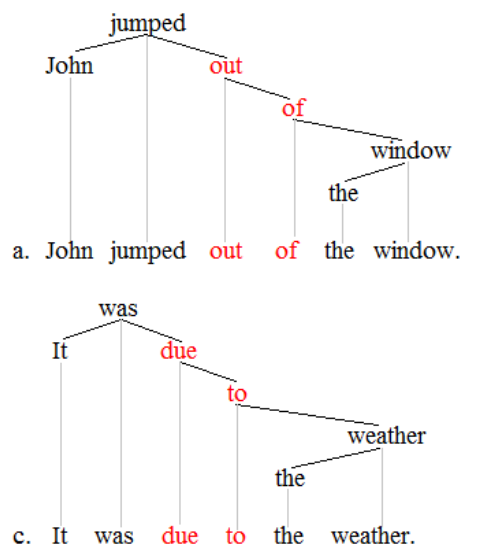

Figure 2. The Demonstration of the Lexical Chunks of interactive teaching method the students as the center of teaching activity.

The Lexical Chunks. Linguist Michael Lewis chunk teaching theory is that, in English, there are a lot of dual characteristic of both the syntax and vocabulary fixed or semi-fixed language structure, the structure of these stereotypes as a whole is stored in the brain for people to extract.

Language communication mainly by the typical words to express basic meaning collocation, use collocation can make the person thinking faster ad make the communication more efficient. So the collocation is very important for the learner, especially those collocations and semi-fixed collocation. When the learners to communicate using collocation, they quickly retrieve large amounts of language from the mental lexicon, reduced the amount of time the brain language processing, accelerate the speed of language output, and improves the accuracy and fluency of language use. Because native speakers will subconsciously when obedient according to each other using phrases match to predict the other party is going to say, more in the oral communication using a fixed collocation can also make up for the general inadequacy of the pronunciation are not allowed to bring, enhance language comprehensibility. Therefore chunk is the important way to realize smooth communication, is one of the main task of foreign language learners [6].
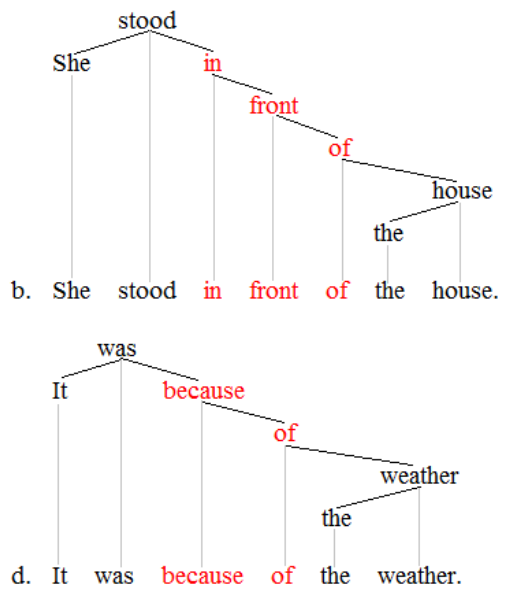
Accordingly, the principles of the lexical chunks education could be summarized as the follows. (1) Teachers in teaching the new words to make its high frequency fixed collocation appear at the same time. To make them aware of some words appear only in limited in some collocation. Students to master the use of these collocation match you need to know their scope and use context. Only on the basis of a certain context, learners can be meaningful learning chunk can be a good understanding and memory. (2) Master the teachers in English teaching should be emphasized among the chunk is an important means of learning English well, and to memorize English words in isolation in a peer or synonyms in Chinese learning method is not desirable, because full meaning, usage, in English and Chinese words are rare, learning words in this way is very difficult to guarantee the learners master the exact meaning of words, let alone grasp its idiomatic usage in English. (3) Teachers should provide students with good enough input material, let the student contact and absorption in accordance with the collocation of English idioms as reading and listening help learners' attention, memory chunk, writing and speaking to give them chance to practice chunk [7].

The British and American Culture. In the context of globalization, the social requirement for the teachers' comprehensive quality is increasing day by day. The merits of the teachers' level of ability of language and literacy to a great extent, affects development of students' cross-cultural communicative competence and if our lack of foreign language teachers' knowledge level, and the function of target language culture and language culture, students are prone to lack of cultural background knowledge in communication, communication difficulties. Therefore, foreign knowledge and multicultural literacy for teachers are equally important. Foreign language teaching, the teacher should keep pace with the times, constantly enrich and perfect themselves, gradually increase to the insight of different culture, guide students to strengthen the sensitivity of cultural differences, to improve students' ability to use English to introduce its culture, so as to improve students' cross-cultural communication ability.

Therefore, in foreign language learning, only have a thorough knowledge of mother tongue culture, has it been possible to understand the profound meaning of purpose language, compared to two kinds of culture deep, do a good job in the cross-cultural communication of two languages to firmly grasp the essence of language knowledge. Otherwise, it is easy to fall into a little knowledge of two kinds of culture, both the embarrassment of ignorance. Therefore, foreign language learners should change the original idea, realize the important role of the mother tongue culture in foreign language learning, strengthen the mother tongue culture to make use of purpose language understanding and expression, and strive to improve their own comprehensive cultural understanding and application ability.

The Enhanced English Education Pattern. Effective development of bilingual teaching for the students to obtain frontier subject in the field of the professional knowledge, master the professional English terms, to improve English, international communication lays the foundation for the future involvement is beneficial to the development of internationalization, talents, colleges and universities in our country the personnel training pattern plays an important role. However, the most of the bilingual teaching practice of colleges and universities of our country reflects the students' English language level, such as teachers' teaching ability is far from satisfy the current situation of bilingual teaching requirements, hindered the bilingual teaching smoothly. Investigate its main reasons in college English teaching and bilingual teaching target, teaching content, teaching methods, learning strategies and so on serious disconnect, difficult to adapt to students from in order to improve English level as the goal of college English 
teaching suddenly learn to speak English as a media professional content of bilingual teaching.

Teaching first to answer what is linguistics, linguistics as a science, what is the relationship between it and other subjects to do an overview of the linguistics, we can see the whole picture of the linguistics and wisdom in the mind is gully. As an independent discipline of the linguistics and other disciplines have very close connection, with linguistics as the center, and sociology, anthropology, psychology, philosophy and form a network. Linguistics and sociology cross form the sociology of language, social linguistics and cultural anthropology formed cross cultural linguistics, linguistics and psychology of cross language psychology or psychological linguistics, linguistics and philosophy of cross form language philosophy. Linguistics to achieve the teaching goal, the first requirement of the linguistics the heuristic teaching method, teachers guide students thinking of love, a good question. Linguistics teaching centering on the problem, the teacher must through the careful design question, inspire the students' questioning mind. Linguistics is not like natural science has a definite answer as linguistics will never be the only answer, just a point. Therefore, teachers should guide students don't always go to accept a point of view, and to take the view angle of the divergence and critical eye, multi-azimuth to carefully examine the different views of the various linguistic schools, points out their respective advantages and disadvantages that puts forward his own unique insights.

Based on this, the modern English language expression of the unlimited and the core means of communication and communication tools, linguistics research is no longer a pure language basic research, should pay more attention to the research of the depth and breadth, which is connected with other subjects, and should be with the interdisciplinary development trend of academic research, broaden the research perspective of the English language, English linguistics in the new era and the further development of the new stage.

\section{Conclusion}

In this paper, we conduct research on the lexical chunks and the interactive education mode and the corresponding applications on the teaching of English linguistics. American management professor Dr. Wells was pointed out that the language interaction is the result of multilateral cooperation and it is made up of these three speakers, receiver, and the context. Interaction between these three alone is related information, is also a process of information processing in the process, the interaction of the participants in context of specific or non-specific, to identify, understand, and processing information and to communicate. With the traditional teaching mode in information only one-way communication between the speaker and recipient, but the real interaction and information transfer between should be multidimensional, participants more, there are teachers, students and there are machines. Our research proposes the novel paradigm for the education which is meaningful.

\section{References}

[1] Hongmei, Li. "Application research of BP neural network in English teaching evaluation." TELKOMNIKA Indonesian Journal of Electrical Engineering 11.8 (2013): 4602-4608.

[2] Kim, Jeong-ryeol, and Jiyun Yang. "An analysis of the continuity of elementary and middle school English textbooks using Coh-Metrix." English Teaching 67.2 (2012).

[3] Jun, Cao. "Discussion on the significance of affective factors in university English teaching and countermeasures [J]." Journal of Nanchang College of Education 1 (2012): 091. 
[4] JIAN, Li-ying, and Xian-chun XIE. "On Interactive Approach of College English Writing Teaching." Journal of Sichuan College of Education 10 (2012): 020.

[5] Klenowski, Valentina. "The Australian curriculum: Implications for teaching and assessment." Primary English Teaching Association Australia 186 (2012): 1-8.

[6] Sherry, Michael Bruce, and Robert Tremmel. "English education 2.0: An analysis of websites that contain videos of English teaching." English Education 45.1 (2012): 35.

[7] Hui, G. U. O. "Cultural Cognition Cultivation Study of College Students Based on the Multi-Modal English Teaching Model." English Language Teaching 2.1 (2015): 30-34. 